\title{
La novedad del concepto de actualidad para el problema de la presencia real de Cristo en la Eucaristía. Un aporte desde la noología de Xavier Zubiri*
}

\author{
Eugenia Colomer E." \\ Pontificia Universidad Católica de Valparaíso \\ Chile \\ Cristián Eichin M. OFM** \\ Pontificia Universidad Católica de Valparaíso \\ Chile
}

Para citar este artículo: Colomer E., Eugenia y Eichin M., Cristián.

«La novedad del concepto de actualidad para el problema de la presencia real de Cristo en la Eucaristía. Un aporte desde la noología de Xavier Zubiri». Fraciscanum 168, Vol. LX (2018): 203-237.

El presente artículo forma parte del proyecto de investigación «La novedad del concepto de actualidad para el problema de la presencia real de Cristo en la Eucaristía. Un aporte desde la noología de Xavier Zubiri», financiado por Stipendienwerk Lateienamerika-Deutschland Intercambio Cultural Alemán - Latinoamericano (ICALA) durante el año 2016 y la colaboración de la Fundación Xavier Zubiri.

Bachiller en Ciencias Religiosas Pontificia Universidad Católica de Valparaíso. Licenciada en Ciencias Religiosas Pontificia Universidad Católica de Valparaíso. Magíster en Filosofía Pontificia Universidad Católica de Valparaíso. Doctora en Filosofía Pontificia Universidad Católica de Valparaíso. Profesora de la Facultad Eclesiástica de Teología, Pontificia Universidad Católica de Valparaíso. Contacto: eugenia.colomer@pucv.cl.

... Bachiller en Ciencias Religiosas Pontificia Universidad Católica de Chile. Licenciado en Teología especialidad Liturgia y Teología de los sacramentos Institut Supérieur de Liturgia, Institut Catholique de Paris, Francia. Doctor en Teología Práctica de la Pontificia Universidad de Salamanca. Profesor de la Facultad Eclesiástica de Teología, Pontificia Universidad Católica de Valparaíso. Contacto: cristian.eichin@pucv.cl. 


\section{Resumen}

La teología sacramental ha realizado su reflexión respecto de la presencia real de Cristo en la Eucaristía y la razón formal de ella desde una metafísica de la sustancia. En el presente artículo se presenta, desde la filosofía zubiriana, otra posibilidad conceptual para la reflexión teológica de la Eucaristía. Nuevos conceptos direccionales que apunten en mejor dirección, por una parte, a precisar el punto radical de lo misterioso del misterio y, por otra, la razón formal de la Eucaristía, cual es la co-corporeidad con Cristo, abarcando las dimensiones individual, social e histórica. Xavier Zubiri trató de manera explícita el tema de la Eucaristía en textos de diversa data y en ellos se muestra cómo el concepto de actualidad va ganando terreno y los alcances que este tiene respecto de la razón formal de la Eucaristía: configurar un solo cuerpo, una sola actualidad.

\section{Palabras clave}

Eucaristía, cuerpo, actualidad, sustantividad, co-corporeidad.

\section{The novelty of the concept of present to the problem of Christ's real presence in the Eucharist. A contribution from Zubiri's noology}

\section{Abstract}

Sacramental theology has made its reflection regarding the real presence of Christ in the Eucharist and its formal reason from a metaphysics of substance. This article presents, from the Zubirian philosophy, another conceptual possibility for the theological reflection of the Eucharist, new directional concepts that point to a better direction, 
on one hand, to precise the radical point of the mysteriousness of mystery and, on the other hand, the formal reason of Eucharist, which is the co-corporeity with Christ from the believer, encompassing its individual, social, and historic dimensions. Xavier Zubiri treated the topic of Eucharist in texts of diverse data in an explicit way, and in them he shows how the concept of present is gaining terrain, as well as the attainments this concept has regarding the formal reason of Eucharist: configuring one body, an only one present.

\section{Key words}

Eucharist, body, actuality, substantivity, co-corporeity.

\section{Introducción}

El presente estudio quiere dar cuenta del aporte del concepto de actualidad del pensamiento zubiriano al problema de la presencia real de Cristo en la Eucaristía, atendiendo al modo de dicha presencia y a la razón formal de la Eucaristía.

El concepto de actualidad va ganando terreno en el desarrollo del pensamiento filosófico de Xavier Zubiri. De acuerdo a la opinión de varios estudiosos del autor actualidad corresponde al concepto central de su filosofía madura ${ }^{1}$, y es de opinión de ellos que el texto 
«Reflexiones teológicas sobre la Eucaristía» (1980) es donde mejor se evidencia el alcance de dicho concepto.

Para el logro de nuestro objetivo realizamos el análisis de tres textos, de diversa data, en los cuales nuestro autor trata de manera explícita el tema de la Eucaristía. Recorriendo estos textos, podremos dejar de manifiesto cómo el concepto de actualidad va alcanzando una importancia capital dentro de la obra del autor, y los alcances que tiene para el problema de la presencia real de Cristo en la Eucaristía y la razón formal de ella. Aquellos textos corresponden a las lecciones viI y VIII del curso en Madrid de 1967 (7 y 11 de diciembre respectivamente), textos inéditos a los cuales hemos accedido con el beneplácito de la Fundación Xavier Zubiri. Contamos además con las lecciones xxiII y Xxiv, impartidas los días 19 y 22 de abril de 1971 en el curso de 26 lecciones impartido en Madrid entre enero y abril de ese año ${ }^{2}$. Y finalmente analizaremos la lección que Xavier Zubiri pronunció en la Universidad de Deusto el $1^{\circ}$ de octubre de 1980, con motivo de su investidura como Doctor honoris causa en Teología, texto que luego fue publicado con el título de «Reflexiones teológicas sobre la Eucaristía»³. Creemos que aquí es donde Xavier Zubiri logra lo largamente buscado por él: la síntesis del hombre y Dios, como co-corporeidad. Donde el «aquí» de la experiencia del hombre y Dios radica en el cuerpo, el cual se comprende primariamente como principio de actualidad de la realidad humana y de la realidad de Cristo. Creemos que los contenidos de su filosofía madura, explícitos en su trilogía de la Inteligencia sentiente (1980-1983) permiten aportar el concepto de actualidad a la aproximación de razón formal de la Eucaristía. A pesar de la novedad que traía su metafísica de la sustantividad frente a la tradicional metafísica de la sustancia, ella no alcanza a tocar lo que el autor buscaba desde su etapa ontológica-metafísica el ser de Dios como ágape y el ser del hombre configurado con él bajo el concepto paulino de deificación.

2 Estas lecciones están recogidas en el libro de Xavier Zubiri, El problema teologal del hombre: Dios, Religión, Cristianismo (Madrid: Alianza, 2015), 670-714.

3 Xavier Zubiri, El problema teologal del hombre: Dios, Religión, Cristianismo, 787-813. 
Los textos de diversa data nos permitirán visualizar los cambios que en el tratamiento del tema se van originando a medida que la filosofía zubiriana va madurando hacia su pensamiento filosófico final, y cómo aquellos conceptos propios de su pensamiento último, particularmente el de actualidad y corporeidad, pueden colaborar a los desafíos que tiene hoy la Teología Sacramental y Pastoral en torno a la Eucaristía.

Xavier Zubiri tuvo presente, en su quehacer filosófico, el horizonte de los problemas teológicos actuales. Para nuestro autor el quehacer teológico no radica en conceptualizar el misterio, el cual por ser misterio no se puede atrapar en conceptos, sino en "precisar cuál es el punto radical en que se halla lo misterioso del misterio» ${ }^{4} \mathrm{y}$ tratar de dar luz a una mejor comprensión de la Revelación. La teología se realiza desde un determinado elenco de conceptos metafísicos y por ende desde una determinada idea de qué sea metafísica. El aporte que puede realizar la filosofía a temas teológicos consiste justamente en aventurarse en una nueva metafísica, acuñando nuevos conceptos que comprendidos siempre de modo direccional apunten de mejor modo al contenido de la Revelación. Así acontece con la metafísica de la sustantividad y de la actualidad zubiriana, la cual trae una novedad conceptual al tema de la Eucaristía, conceptos direccionales que dan mejor cuenta de la presencia real y de la razón formal de ella. Creemos que es esta última la que es mejor alcanzada por el concepto de actualidad. Es esto lo que trataremos de desarrollar en este artículo.

Ahora bien, hay varios estudios que tratan la Eucaristía desde la perspectiva de la filosofía zubiriana ${ }^{5}$, dentro de ellos el más cercano a nuestra propuesta es el de José A. Millás (2000) sin embargo,

4 Xavier Zubiri, El problema teologal del hombre: Dios, Religión, Cristianismo, 787.

5 Francisco Sotil, «La conceptuación zubiriana de la presencia eucarística de Cristo: críticas y valoración de las mismas», The Xavier Zubiri Review, 9, (2007): 19-68; José A. Sayés, La presencia real de Cristo en la Eucaristía, (Madrid: Biblioteca de Autores Cristianos, 1976); Félix Alluntis, «Reflexiones teológicas sobre la Eucaristía de Xavier Zubiri», Estudios Eclesiásticos, 63 (1988); José M. Millás, «Zubiri y la Eucaristía. La aplicación de los conceptos de actualidad y sustantividad a la teología de la Eucaristía», Gregorianum, 81, 2 (2000): 249-285; José A. Sayés, «La transubstanciación en Zubiri: ¿Realismo o fenomenología?», Ciencia Tomista 127 (2000): 393-414. 
el mismo autor, en su conclusión, alienta a seguir profundizando respecto de la razón formal de la Eucaristía: comunión interpersonal de los comensales con Cristo y por tanto incorporación a su cuerpo ${ }^{6}$. Pues bien, nuestro interés apunta allí, porque creemos que los estudios realizados en torno al tema de la Eucaristía y la filosofía zubiriana, permiten profundizar en la unidad corpórea de Cristo y quienes comparten el banquete eucarístico, y donde el concepto de actualidad nos parece gravitante como aporte. El esfuerzo por buscar nuevos conceptos direccionales, que se acerquen mejor a la razón formal de la Eucaristía se ve acicateado por la situación de desafección de los creyentes respecto a la vida sacramental eucarística. Si son los hechos los que dan que pensar, la teología no puede ser indiferente ante esta desafección de la participación litúrgica en la celebración eucarística; el pensamiento teológico se encuentra desafiado a volver a mirar los conceptos con los cuales se ha acercado al misterio e indagar por otros que, de mejor modo, se aproximen a la unidad a la cual llama la Eucaristía: un solo cuerpo.

\section{Aproximación al estado de la reflexión teológica sobre la presencia real de Cristo en la Eucaristía}

La discusión sobre la presencia real de Jesucristo tiene su historia. La práctica de la adoración de la presencia real en la Eucaristía llegó a su culmen en la Edad Media con diversas manifestaciones litúrgicas y populares: elevación de la hostia consagrada, la fiesta de Corpus Christi, el culto eucarístico fuera de la Misa ha llegado hasta nosotros como testimonio del reconocimiento de la presencia de Jesús en la Eucaristía bajo las especies de pan y vino. Es en el siglo xvi el Concilio de Trento donde se pronuncia al respecto y señala que «después de la consagración del pan y del vino, se contiene verdadera, real y sustancialmente nuestro Señor Jesucristo, verdadero Dios y hombre,

6 José M. Millás, «Zubiri y la Eucaristía. La aplicación de los conceptos de actualidad y sustantividad a la teología de la Eucaristía», 284. 
bajo la apariencia (sub specie) de aquellas cosas sensibles» ${ }^{7}$. Además, define la transubstanciación como la "conversión (conversio) de toda la sustancia del pan en la sustancia del cuerpo de Cristo nuestro Señor, y de toda la sustancia de su sangre» ${ }^{8}$. La transubstanciación viene a ser la condición de posibilidad de la presencia real y sacramental de Cristo glorioso en la Eucaristía. De esta manera, el Concilio de Trento propone categorías hilemórficas para afirmar el modo de la presencia de Cristo. Lleva adelante una definición dogmática que llega hasta nuestros días.

Sin detallar los debates teológicos presentes entre Trento y el siglo $\mathrm{xx}^{9}$ nos centraremos en el siglo $\mathrm{xx}$, donde grandes teólogos europeos, y gracias a los distintos movimientos eclesiales y teológicos de aquella época, revisaron las categorías filosóficas y teológicas de la interpretación del cómo de la presencia de Cristo en la Eucaristía. Entre los que más destacan: Odo Casel con su texto «El misterio del Culto cristiano» ${ }^{10}$ y la relación que hace del misterio con las especies de pan y vino; Karl Rahner ${ }^{11}$ y la relación que hace entre la teología del símbolo con la presencia real simbólica o Henri de Lubac ${ }^{12}$ en donde coloca en íntima relación Eucaristía e Iglesia. Desde Holanda la figura del belga Eduard Schillebeeckx con su libro «La presencia real de Cristo en la Eucaristía» (1968) ${ }^{13}$ señala que «es preciso conservar el estadio de fe, el ontológico, pero no el de la filosofía de la naturaleza o comprensión física ${ }^{14}$ para entender el cómo de la conversión en las especies eucarísticas.

7 Heinrich Denzinger, Peter Hünermann, El Magisterio de la Iglesia. Enchiridion Symbolorum definitionum et declarationum de rebus fidei et morum (Barcelona: Herder, 2006), n 1636.

8 Heinrich Denzinger, Peter Hünermann, El Magisterio de la Iglesia. Enchiridion Symbolorum definitionum et declarationum de rebus fidei et morum, $\mathrm{n}^{\circ} 1642$.

9 Estos debates se detallan en: Dionisio Borobio, La Eucaristía (Madrid: Biblioteca de Autores Cristianos, 2005) 298-301.

10 Odo Casel, El misterio del culto cristiano (San Sebastián: Dinor, 1953).

11 Cf. Karl Rahner, Escritos de teología, Tomo Iv, (Madrid: Taurus Ediciones, 1964), 283-321; 367-396.

12 Cf. Henri de Lubac, Corpus Mysticum. L'eucharistie et l'Eglise au Moyen Âge (Paris: Éditions du Cerf, 2010).

13 Edward Schillebeeckx, The Eucharist (New York: Burns \& Oates, 1968)

14 Citado en: Dionisio Borobio, La Eucaristía (Madrid: Biblioteca de Autores Cristianos, 2005), 3003001. 
En este tiempo surgen, con sumo interés, algunas reflexiones teológicas influidas por las nuevas corrientes filosóficas como la existencial, la personalista y la fenomenológica. Ellas hablan de nuevas categorías para entender este cambio, a saber: transfinalización y transignificación ${ }^{15}$. Podemos preguntarnos qué comprensión teológica encontramos detrás de estas nuevas apuestas. Ante todo, se recalca que, bajo las especies eucarísticas, se hace presente Cristo resucitado, el Cristo glorioso que se da a sí mismo y que es portador de la salvación a la comunidad creyente, es decir, una donación, una presencia para la comunidad celebrante que se da.

Ante estas búsquedas propias del quehacer teológico, el Magisterio de la Iglesia se pronuncia en varios documentos. Pío XII, en la Humani generis $\mathrm{n}^{\circ} 20$ del año 1950, condena las doctrinas que sostienen que el concepto de transubstanciación es anticuado y así reducen su presencia a puro simbolismo. Y es con Pablo VI, en su encíclica Mysterium fidei del año 1965 que reafirma que la presencia real de Jesucristo es gracias a la transubstanciación, y no por la transfinalización y transignificación. Por tanto, el Magisterio apuesta más por la ontologización de la presencia de Jesús en la Eucaristía que por algunas hermenéuticas subjetivas o significativas ${ }^{16}$. «Con todo, el cambio "ontológico" que afirma Pablo VI no tiene porqué entenderse como cambio físico... lo que está diciendo es que el "cambio" no sucede solo en el "ser para", en el significado, sino en la realidad ${ }{ }^{17}$. Es claro que este tiempo nos encontramos a una reivindicación de la transubstanciación como clave filosóficateológica para comprender la Eucaristía, pero ¿̇será la única forma de aproximarnos a lo que ocurre en el pan y en el vino?

Remontándonos al Concilio Vaticano II nos encontraremos con una toma de posición interesante y abierta con respecto a la presencia

15 Un detallado estudio sobre el estado de la cuestión teológica de la Eucaristía en el siglo XX, aun con sus posiciones no favorables a la fenomenología y hermenéutica, lo podemos encontrar en: José Antonio Sayés, El Misterio Eucarístico (Madrid: Ediciones Palabra, 2003), 413-445.

16 Cf. José Aldazábal, La Eucaristía (Barcelona: Centre de Pastoral Litúrgica, 1999), 320

17 José Aldazábal, La Eucaristía, 320. 


\section{y presencias de Cristo en la Iglesia. En la primera constitución conci- liar Sacrosanctum Concilium, se afirma sobre la presencia de Cristo:}

Para llevar a cabo una obra tan grande, Cristo está presente en su Iglesia, principalmente en los actos litúrgicos. Está presente en el sacrificio de la misa, no solo en la persona del ministro, «ofreciéndose ahora por ministerio de los sacerdotes el mismo que entonces se ofreció en la cruz», sino también, sobre todo, bajo las especies eucarísticas. Está presente con su virtud en los Sacramentos, de modo que, cuando alguien bautiza, es Cristo quien bautiza. Está presente en su palabra, pues es Él mismo el que habla cuando se lee en la Iglesia la Sagrada Escritura. Está presente, finalmente, cuando la Iglesia suplica y canta salmos, el mismo que prometió: «Donde están dos o tres congregados en mi nombre, allí estoy Yo en medio de ellos» $(\mathrm{Mt} 18,20)^{18}$.

Como leemos en la Constitución sobre la liturgia, la presencia de Cristo se manifiesta en distintos momentos de la vida litúrgica: en primer lugar, en la Eucaristía (ministro, bajo las especies eucarísticas) ${ }^{19}$, en la fuerza de los sacramentos, en la Palabra proclamada más que en el libro de las lecturas, en la asamblea que celebra. A este aporte del Concilio Vaticano II se agrega otra manifestación de la presencia de Cristo en la Iglesia: los pobres ${ }^{20}$. Es decir, la presencia del único Cristo no solo está presente de manera real bajo las especies eucarísticas, sino en otras mediaciones por él señaladas en los Evangelios:

Hablar de presencia «real» en la Eucaristía y concentrarla en las especies eucarísticas, induce de manera espontánea la sensación de que las demás presencias del Señor no son reales, sino meramente imaginarias o simbólicas (en el sentido más débil de «simple simbolismo»). De ese modo, quedaría olvidada una de las verdades más fundamentales y consoladoras del cristianismo, a saber, que, desde su identificación con Dios a partir de la resurrección, Cristo está realmente presente allí «donde dos o tres

18 Concilio Vaticano II, Constitución Sacrosanctum Concilium sobre la sagrada liturgia, 4 de diciembre 1963, n. 7 (Madrid: Biblioteca de Autores Cristianos, 1993), 190.

19 «se llama "real" no por exclusión, como si las otras presencias no fueran "reales", sino por antonomasia, porque es substancial». SS Juan Pablo II, «Exhortación apostólica postsinodal Ecclesia in America», $\mathrm{n}^{\circ}$ 12, consultada en mayo 27, 2017, http://w2.vatican.va/content/john-paul-ii/es/apost_ exhortations/documents/hf_jp-ii_exh_22011999_ecclesia-in-america.html. Bajo las especies de pan y vino, «Cristo todo entero está presente en su "realidad física" aun corporalmente», SS Juan Pablo II, «Exhortación apostólica postsinodal Ecclesia in America», n 12.

20 SS Juan Pablo II, «Exhortación apostólica postsinodal Ecclesia in America», n 12. 
se reúnen en mi nombre» (Mt 18,20) y allí donde toda persona de buena voluntad — «todos los benditos de mi Padre» (Mt 25,34-36) — trabaja por el amor y la justicia ${ }^{21}$.

Entonces, la presencia verdadera, real y sacramental del Cuerpo glorioso de Cristo está ubicado en un contexto más amplio: toda celebración litúrgica es interpretada bajo la categoría de presencia de Cristo, pero siempre teniendo como el modo por excelencia la de las especies eucarísticas.

También podemos decir que el tema planteado sobre «transubstanciación», «transfinalización», «transignificación», que se produjo en la década de los sesenta, quedó zanjada por el Magisterio bajo el concepto de «transubstanciación». Esto no impidió a seguir en los teólogos algunas búsquedas de conceptos de acuerdo a la filosofía contemporánea: explicar el cambio en términos de «relación», «diafanía» o transparencia de lo real para verlo fundado en Dios (Theilard de Chardin) ${ }^{22}$. Desde el punto de vista teológico queda abierta la cuestión sobre el modo de comprender la realidad de la presencia de Cristo en la Iglesia.

Si bien las búsquedas de la teología de la Eucaristía no han estado exentas de tensiones, el mismo Magisterio ha estimulado a la Teología a seguir profundizando en este Misterio, tal como lo planteó el papa Pablo VI en su Encíclica Mysterium Fidei (1965). Para avanzar en su reflexión, la teología de la Eucaristía debe dialogar con nuevos presupuestos filosóficos, los cuales pueden aportar una novedad conceptual al tema y así dar mayor luz a lo que Dios quiso revelar en la institución de la Eucaristía. En el fondo se trata de aproximarse a la razón radical de la Eucaristía, cual es la prolongación de la Encarnación en ella para la configuración personal con Cristo de modo individual, social e histórico, de todos quienes la reciben.

\footnotetext{
21 Andrés Torres Queiruga, «La Eucaristía, encuentro vivo con el Señor», Horizonte: Revista de Estudos de Teologia e Ciências da Religiao, 12 (2008), 25, consultada en enero 7 de 2017, dialnet.unirioja.es/ descarga/articulo/4740639.pdf

22 Citado en: Andrés Torres Queiruga, «La Eucaristía, encuentro vivo con el Señor», 34-38.
} 
Esta investigación pretende tocar nuevamente el tema de la presencia real, sacramental de Cristo en la Eucaristía, en fidelidad al Magisterio y en fidelidad a las preguntas pastorales del hombre de hoy. Y lo hacemos en diálogo con la filosofía de Xavier Zubiri, porque se acercó al tema de la Eucaristía atendiendo a los datos de la fe, y prestando atención a no dogmatizar los conceptos, por muy plausibles que sean, porque siempre se encuentran en un carácter de provisionalidad, por ser fruto del esfuerzo del intelecto humano. La filosofía, como lo propio de su quehacer, acuña nuevos conceptos; a través del tiempo la teología ha hecho uso de ellos. Es por lo anterior que los conceptos utilizados para tratar la presencia verdadera, real y sacramental de Jesús glorioso en la Eucaristía pone en evidencia que aquí se implican conceptos no puramente teológicos, estos presentan una carga desde una determinada metafísica, y desde un determinado horizonte de intelección, pero la doctrina sobre la Eucaristía no exige fidelidad absoluta a una determinada metafísica, sino fidelidad a la experiencia de que Jesús permanece con nosotros hasta el final de los tiempos, como donación permanente para configurar nuestro ser con Él y una fidelidad a las interrogantes del hombre de hoy que busca conocer sobre su fe.

\section{Reflexiones filosóficas de Xavier Zubiri en torno a la Eucaristía}

\subsection{El problema del logos predicativo}

Las reflexiones filosóficas en torno a la Eucaristía, al interior de la obra zubiriana, comienzan siempre atendiendo al dato bíblico, poniendo atención al problema de la traducción del texto de la institución de la Eucaristía. En el curso de 1967 nos pone sobre aviso respecto a las palabras de Jesús en la cena donde instituye la Eucaristía, sea que fueran pronunciadas en Arameo (sería lo más verosímil) sea en hebreo, ellas no envolvían el verbo ser porque es una lengua nominal. Poner atención, de inicio, al problema del logos predicativo es gravitante en el tema que nos convoca. Si bien aquí solo 
le dedica unas pocas palabras, este tendrá mayor espacio en sus textos posteriores, particularmente en el texto de 1980. Detengámonos en este último.

Allí analiza la frase bíblica paulina: toûtó moú estìn tò sóma, traducida del griego como «esto es mi cuerpo» $(1$ Co 11,24$)$ y nos dice:

Aquella frase tiene tres partes. Primeramente, sóma, que el latín tradujo por corpus, cuerpo. Pero Cristo no se expresó ni en latín ni en griego, sino en arameo. Sôma traduce el arameo guph, o también basar, que significan ciertamente cuerpo, pero no solo como parte material del hombre (es decir, no es el cuerpo como diferente del alma), sino que designan el hombre completo entero, "yo mismo»... En el propio griego, la palabra sôma expresa a veces el "yo mismo», como puede verse en algunos pasajes de San Pablo. Entonces la frase de San Pablo habría de traducirse: «esto soy yo mismo». La frase tiene un sujeto: toúto, «esto». En arameo da, en hebreo ze, significan «este, esto»; pero pueden significar a veces también «aquí». Las dos posibilidades no se excluyen a mi modo de ver porque se trata siempre de «esto que está aquí». Sea cualquiera la traducción que se adopte, la frase dice «esto (aquí) soy yo mismo». Finalmente, en la frase griega está el verbo ser, esti. Ahora bien, en arameo y hebreo no hay cópula verbal; la frase es puramente nominal. Es esfuerzo perdido todo cuanto se ha discutido acerca del sentido del «es» en la frase de la institución eucarística. Por tanto, habrá que traducir: «esto (aquí), yo mismo». La frase nominal expresa la realidad misma con mucha más fuerza que la frase verbal copulativa ${ }^{23}$.

¿Por qué la frase nominal expresa con más fuerza la realidad que la frase verbal copulativa? Bajo el análisis descriptivo del acto de sentir, desde donde surge la intelección como un acto intelectivosentiente, la realidad se nos impone en su carácter físico y constructo, por tanto, un logos que quiera dar cuenta de ella debe expresar, tocar el carácter físico de aquellas notas. En nuestro texto la diferencia entre la expresión semítica y la helena radicaba, que la primera prescinde del verbo ser, apareciendo el verbo estar, «esto que está aquí, Yo mismo», a diferencia de "toûtó moú estìn tò sóma» "Esto es mi cuerpo». Pudiese parecer que la distinción entre estar y ser estaría

23 Xavier Zubiri, El problema teologal del hombre: Dios, Religión, Cristianismo, 789-790. [el subrayado es nuestro] 
en la dimensión transitoria y permanente que denotan estos verbos, el mismo autor nos dice que esto es verdad, pero ese mismo carácter más o menos transitorio hace aparecer en primer plano su carácter de actualidad física. «De suerte que la contraposición entre "ser" y "estar" no es primariamente la contraposición entre lo permanente y un estado transitorio, sino la diferencia entre "ser" sin alusión al carácter físico, y el "estar" como realidad física»" ${ }^{24}$. De acuerdo a lo anterior, podemos deducir que la fuerza de la frase nominal radica en tocar el carácter físico de la realidad aprehendida impresivamente.

Las lenguas históricas no expresan la realidad de la misma manera y por ende no tienen la misma comprensión de ella. Esto queda claro en el análisis de 1Co 11, 24. Aquella frase muestra de manera paradigmática el problema del lenguaje. El logos predicativo expresa una realidad escindida y subjetual y se ha identificado como el único logos posible. Zubiri, conocedor de otras lenguas, hace presente que hay otros logos que expresan la realidad misma de modo no subjetual, viendo nuestro autor en el logos nominal constructo un modo de expresión de la realidad que da mejor cuenta de ella en tanto no la escinde y expresa con mayor fuerza ese físico estar que mienta lo real, tal es el logos propio de las lenguas semíticas, mundo al cual pertenecía Jesús.

Zubiri comienza atendiendo al problema del lenguaje, porque en el "estado constructo" ha encontrado un organon adecuado para la expresión de la realidad misma como constructa. "No se trata, pues, de una mera descripción o ilustración lingüística, sino de una estructura real y física, independiente de las vicisitudes de su expresión gramatical» ${ }^{25}$. Esta estructura de la realidad surge del análisis descriptivo del acto del inteligir, y desde aquí dos conceptos gravitantes para el tema de la Eucaristía: sustantividad y actualidad. Conceptos que, según el autor, apuntan direccionalmente mejor a la razón formal de la Eucaristía, cual es la co-actualidad o co-corporeidad

24 Xavier Zubiri, Inteligencia y logos (Madrid: Alianza, 1982), 234.

25 Xavier Zubiri, Inteligencia y logos, 293. 
con Cristo. De ahí la importancia de atender sintéticamente a estos conceptos desde su filosofía madura.

\subsection{La realidad como sustantividad}

El punto de partida de la filosofía primera de Xavier Zubiri es la descripción del acto de inteligir, este se nos presenta como aprehensión impresiva de realidad. La realidad se siente, se nos da «físicamente», lo que aprehendemos son diversas notas que se integran en la realidad aprehendida.

Lo real tiene, pues, un momento de realidad (el «de suyo»), y otro momento de contenido autonomizado. Pues bien estos dos momentos no son independientes. Para verlo basta con atender a la sustantividad sistemática. Vuelvo a decir que no se trata de construir conceptos teoréticos, sino de llevar a cabo el análisis atento de cualquier aprehensión de lo real. En la sustantividad sistemática, la unidad del sistema constituye un in, su intus, su interioridad. Aquí interioridad no significa algo oculto por debajo de las notas, sino que es tan solo la unidad misma del sistema de ellas. La unidad es lo que hace de estas notas un constructo: ser «notas-de» el sistema. Las notas por sí misma son la proyección de la unidad misma: son su «ex», su «extra», su exterioridad. Toda realidad es así un in y un ex, interioridad y exterioridad ${ }^{26}$.

Por más simple que sea la nota ella se presenta en la aprehensión dos momentos, el de contenido como el más obvio, y es a lo que atendió la filosofía griega y medieval, pero también tiene otro momento, un modo de «quedar» en la impresión, este modo de quedar es lo que nuestro autor llama formalidad, la forma como el contenido queda en la aprehensión como radicalmente otro. De modo particular en el acto de aprehensión impresiva «lo otro» queda como perteneciendo «en propio», «de suyo», como siendo «en propio» lo que es. Realidad es por tanto formalidad, «reidad» (neologismo de Zubiri), el «de suyo» sentido en la aprehensión impresiva. La nota nos remite al «de suyo», pero debe haber un contenido que tenga capacidad para ser «suyo», capacidad para «quedar» como independiente del aprehensor, es lo que Zubiri llama «suficiencia constitucional», y 
constituye la sustantividad. "Como cada una es "nota-de" todas las demás del sistema, resulta que las notas forman un sistema cíclico, un sistema con clausura que es cíclica (...) el sistema clausurado y cíclico de notas constitutivas es lo que constituye la sustantividad ${ }^{27}$. Lo interesante es que la sustantividad puede perderse o adquirirse, sin cambiar de propiedades, para clarificarlo Zubiri toma su clásico ejemplo de la glucosa; ella fuera del organismo en un frasco es una sustantividad, en cambio al ser ingerida es insustantiva sin haber perdido ninguna de sus propiedades, es nota-de otra sustantividad, el organismo humano ${ }^{28}$.

Ahora bien, las cosas también constituyen una estructura constructa respecto de la vida humana. Así Zubiri distingue la «Cosa-realidad» de la «cosa-sentido». La primera no tiene respecto para la vida humana, en el caso del pan, como nuda realidad. En cambio el pan en cuanto cosa-sentido constituye el pan-alimento, se halla en estado constructo respecto de la vida humana ${ }^{29}$. Pero, para constituirse en cosa-sentido debe la cosa-realidad tener condición para ello, por ejemplo el agua no tiene condición para ser una puerta.

\subsection{La actualidad como devenir de la realidad: ser y cuerpo}

La actualidad Zubiri la define como un «estar presente desde sí mismo por ser real»» ${ }^{30}$. Aquí el «estar» es lo clave del concepto, lo presente está subordinado al físico estar por ser real. Cuando aprehendemos una cosa real en tanto real estamos sintiendo el «de suyo» en la aprehensión, pero anterior a ella. Entonces, si la actualidad es aquel «estar presente» de lo real en tanto real, la actualidad lo es siempre del «de suyo». La realidad es dinámica por ser respectiva, el verbo «estar» si bien detenta un carácter físico también detenta un carácter dinámico.

27 Xavier Zubiri, Inteligencia Sentiente/Inteligencia y Realidad, 46.

28 Cf. Xavier Zubiri, El problema teologal del hombre: Dios, Religión, Cristianismo, 794.

29 Cf. Xavier Zubiri, El problema teologal del hombre: Dios, Religión, Cristianismo, 795.

30 Xavier Zubiri, Inteligencia Sentiente/Inteligencia y Realidad, 139. 
Pero actualidad no es actuidad, ni es mera presencia, sino que la presencia a que aquí me refiero consiste en que lo real, por ser real, es desde sí mismo y «en propio» real «actual»: no es presencia, sino un estar presentándose en cuanto estar. La apertura de la realidad es ahora respectividad como actualidad. La respectividad constituyente es el fundamento de toda actualidad. Ahora bien, entre las muchísimas actualidades que lo real puede tener y tiene hay una que es primaria y fundamental, y que, por tanto, es suprema actualidad: es la actualidad de la cosa real en el mundo, en ese mundo que ella misma ha determinado dentro de sí misma por respectividad constituyente. Y la actualidad de lo real en el mundo es justo el ser ${ }^{31}$.

Las mismas notas de un sistema sustantivo en unidad constructa, pueden ser comprendidas como presentándose entre sí, y la co-presentación entre ellas es ese «de» del estado constructo, así el contenido de cada nota es real solo desde la realidad del sistema. «La actualidad es siempre el carácter de una realidad respecto de otra, y este respecto es "presencia" de algo en algo»" Hay un tipo de actualidad, donde lo real no está presente para sí mismo sino presente en el mundo, y esto es el ser como actualidad mundanal. De este modo, hay dos actualidades. Una es la actualidad de la cosa en su realidad. Y otra es la actualidad de esa cosa en el mundo. La segunda actualidad está fundada en la primera, lo que significa que el ser está fundado en la realidad. Para Zubiri, la realidad es algo que está más allá del ser. El ser es la actualidad ulterior de lo real en el mundo, y en este sentido, el ser es algo que pende de la realidad de las cosas, y no al revés. Para alcanzar las cosas no es necesario una previa comprensión del ser, se trata más bien de lo inverso, la impresión de realidad es el origen radical de toda intelección del ser de las cosas. Ahora bien, ¿́qué mienta esta nueva comprensión del ser para la realidad humana?

En cuanto al ser de la realidad humana, podemos afirmar que la actualidad en el mundo de lo real es lo que constituye el ser. La realidad humana, como todo lo real, es un sistema de notas, pero que 
conlleva una particularidad, ya que en ella se diferencian dos subsistemas, el sub-sistema físico y el sub-sistema psíquico, donde la nota fundamental de este último es la inteligencia, así la sustantividad de la realidad humana es psico-orgánica. Por su nota intelectiva es una realidad abierta, reduplicativamente «de suyo», un «de suyo» que se sabe tal. El hombre tiene como forma de realidad, el ser suyo, suidad (soy mío), es lo que constituye la personeidad, modo de ser real, el cual siempre es el mismo, lo que cambia es la personalidad, la cual corresponde a las modulaciones que va adquiriendo la personeidad. Se es persona en el sentido de personeidad por el mero hecho de ser realidad humana, de tener inteligencia, ello define al hombre como un animal personal. En cuanto a su modo de implantación en la realidad, es un absoluto relativo. Es absoluto porque es suyo frente a toda realidad posible, pero es relativo, porque este modo de implantación absoluto es un carácter cobrado a la realidad misma, el hombre la requiere como posibilitante para ser de un modo u de otro. En cada acto el hombre va realizando su ser; el ser de la realidad humana surge en cada acto en cuanto apropiación de posibilidades.

La actualidad mundanal de esta realidad relativamente absoluta es la que llamamos "yo». El yo no es sujeto, sino predicado, esa realidad soy yo. El yo es el ser de lo relativamente absoluto. «El Yo no es primario; lo primario es la realidad. Y precisamente por ello, el Yo refluye sobre mi propia realidad, y constituye esa unidad de ser y realidad que llamamos "Yo mismo". Es justo la "realidad siendo"»>33.

Para Zubiri el yo tiene una dimensión natural, el yo es un momento de actualidad de la realidad humana, por lo tanto, el yo es el ser. Así entendido, el yo no es anterior al ejercicio de la inteligencia como lo ha propuesto la modernidad. En el sistema no hay ningún substrato «tras» o «bajo» las notas, sino que solamente nos encontramos con estas notas en su versión radical de unas a 
otras. Ahora, podemos fundamentar mejor la traducción de la frase bíblica «Este es mi cuerpo» como «Esto Yo mismo».

Atendido el ser de la realidad humana, detengámonos en el cuerpo humano respecto al ser. ¿Qué mienta el cuerpo en este Yo ya no subjetual?

Si el concepto de actualidad trae una novedad al ser de la realidad humana también la tiene para el concepto del cuerpo ${ }^{34}$.

El hombre no «tiene» cuerpo, sino que «es» corpóreo. Por esto su actualidad corpórea pertenece a la realidad humana misma, no solo intrínsecamente, sino también formalmente. El hombre no se «hace» presente por su cuerpo, sino que por su cuerpo «está ya» presente. Y en otras dimensiones, este tipo de actualidad intrínseca y formal es propio de toda realidad en cuanto tal: es el ser. Es un tema en el que no puedo entrar aquí. Tan solo dejo taxativamente consignado que hoy estamos necesitados también de una metafísica de la actualidad; no nos es suficiente una metafísica del acto ${ }^{35}$.

El cuerpo comprendido como corporeidad, se nos presenta como principio de actualidad, principio que mienta funcionalidad. La función del cuerpo es hacer presente nuestra realidad en el mundo por el hecho que somos reales. De allí que podamos afirmar «ese cuerpo soy yo, mi realidad siendo».

Desde la novedad que trae la inteligencia sentiente a los conceptos de ser y cuerpo, podemos aproximarnos de otro modo la presencia real de Cristo en la Eucaristía y su razón formal. Vayamos por pasos contados a ver cómo se fue atendiendo al tema al interior de su obra.

34 Sobre la novedad respecto del cuerpo y la dimensión teologal del hombre ver Eugenia Colomer y Ricardo Espinoza, "Cuerpo y religación en Xavier Zubiri», Teología y Vida, 2, 56 (2015): 247-270.

35 Xavier Zubiri, El problema teologal del hombre: Dios, Religión, Cristianismo, 801. Cabe consignar que resulta clave en el tratamiento del cuerpo y la unidad de la realidad humana, dentro del pensamiento zubiriano, el texto de 1973 «El hombre y su cuerpo» en Escritos menores (1953-1983) (Madrid: Alianza, 2006), 103-116. 


\subsection{La presencia real de Cristo en la Eucaristía}

\subsubsection{La propuesta en los cursos de 1967 y 1971}

Cabe hacer notar que el texto de 1967 se redacta muy cerca de la promulgación de la Carta Encíclica Mysterium fidei sobre la doctrina y el culto de la Eucaristía, del papa Pablo VI, el 3 de septiembre de 1965. Allí se zanjó, como explicamos al comienzo, la cuestión de la presencia real de Cristo, pero a la vez afirma que es verdad «que dichas fórmulas se pueden explicar más clara y más ampliamente con mucho fruto ${ }^{36}$, siempre que se mantengan intactas las verdades de fe.

En ambos textos comienzan atendiendo al texto bíblico de la institución de la Eucaristía, ello porque este entrega «una gran luz sobre lo que constituye la revelación misma de la Eucaristía, y el Dogma definido» ${ }^{37}$. En la lección de 1967 solo resalta que la frase nominal: den bisar, «Esto, mi carne». Expresa de modo más fuerte que con el verbo ser, la realidad. Será en el texto de 1971 donde nos pondrá en aviso sobre el uso de la palabra $\sigma \alpha ́ \rho \xi$ (carne) en vez del vocablo $\sigma \tilde{\omega} \mu \alpha$, detalle no menor porque deja remitida la corporeidad a la carnalidad, siendo esto uno de los grandes errores por los cuales se ha deslizado la teología en la Edad Media ${ }^{38}$. Y esto tiene importancia para la definición del dogma. Es una frase absolutamente realista: da besari. Ya expusimos anteriormente el tratamiento más extenso, y con los supuestos de su filosofía última, que realiza el autor respecto a los alcances que tiene el desatender los conceptos desde la metafísica semita, traducirlos y comprenderlos desde una metafísica ajena a ella.

Una vez atendido el problema del logos predicativo, presenta una crítica al concepto de sustancia, concepto clave en la reflexión teológica respecto a la Eucaristía. ¿̇Es el concepto de sustancia el

Pablo VI, Carta Encíclica Misteryum fidei, 3 de septiembre de 1965, n 3 . Consultada en mayo 27, 2017, http://w2.vatican.va/content/paul-vi/es/encyclicals/documents/hf_p-vi_enc_03091965_mysterium.html

37 Curso «Reflexiones filosóficas sobre algunos problemas de teología», VII lección, Madrid, 7 de diciembre de 1967. Texto inédito.

38 Cf. Xavier Zubiri, El problema teologal del hombre: Dios, Religión, Cristianismo, 678. 
mejor concepto direccional para atender a la presencia real de Cristo en la Eucaristía y a la razón formal de ella? La vía propuesta a esta altura es otra, es la metafísica de la sustantividad.

La Eucaristía ha sido tratada desde una determinada comprensión de las cosas, entendidas como sustancias, sin embargo, ello es una teoría, y como tal siempre provisional. Para Zubiri las cosas no son sustancias sino sistemas de notas. Para que se conforme una sustantividad debe haber notas constitutivas suficientes y necesarias que determinan una unidad clausurada. Ahora bien, la sustantividad se puede adquirir o perder. De allí que la distinción de la realidad es entre sustantivo o insustantivo.

Desde la metafísica de la sustantividad la conversión eucarística:

(...) consiste en que Cristo toma, para su propia unidad y sustantividad, en que consiste su realidad de Cristo, (exactamente como la unidad y la sustantividad del pan es aquello en que consiste la realidad del pan) toma, digo, precisamente, para su unidad y sustantividad, la de su cuerpo (esa unidad primaria y radical en que consiste, y que se plasma precisamente en todas las notas y propiedades que puede tener su cuerpo glorioso ${ }^{39}$.

Las especies del pan y el vino adquieren una nueva sustantividad, la sustantividad de Cristo, es una transubstantivación. Y esto por la acción de Cristo, quien «toma para sí, es decir, ejecuta la acción de tomar las notas del pan para conferirles una nueva sustantividad $»^{40}$. Cristo está realmente presente en la Eucaristía por la conversión de la unidad coherencial primaria en que el pan consiste. Ese sistema clausurado y total, la sustantividad del pan, en cierto modo queda abierto por Cristo a una sustantividad de orden superior. En ello radica el misterio: abrir la unidad coherencial primaria del pan a una unidad superior, «la propia unidad sustantiva de Cristo» ${ }^{41}$. De este modo las notas del pan se constituyen en vehículo y no mero

39 Curso «Reflexiones filosóficas sobre algunos problemas de teología», VIII lección, Madrid, 11 de diciembre de 1967. Texto inédito.

40 Curso «Reflexiones filosóficas sobre algunos problemas de teología», VIII lección.

41 Curso «Reflexiones filosóficas sobre algunos problemas de teología», VIII lección. 
continente de la sustantividad divina ${ }^{42}$. Las especies actualizan significativamente, en razón alimento, pero también físicamente, la unidad del cuerpo de Cristo.

El relato bíblico muestra los tres aspectos de la Eucaristía: un aspecto de recuerdo o memorial, una presencia real, y una prenda escatológica. Poniendo énfasis, tal como lo ha realizado la Iglesia desde siempre, en el carácter de una presencia actual y sensible. La Eucaristía es un sacramento, y por tal un signo sensible, eficaz (producen su efecto, ex opere, operato) y debe realizarse in persona Christi; en la persona de Cristo. En el sacramento hay algo producido por el sacramento mismo; y en este caso, se produce una presencia real del cuerpo de Cristo en el pan, y del alma de Cristo en el vino. Con estos elementos el Concilio de Trento define dogmáticamente el sacramento de la Eucaristía ${ }^{43}$. Allí se afirma la presencia física de la realidad de Cristo obtenida por una conversión; la conversión de la sustancia toda del pan en la sustancia del cuerpo de Cristo, manteniendo, sin embargo, las especies, de las cuales el Concilio no dice qué $\operatorname{sean}^{44}$. Si bien, afirma Zubiri, sería improcedente atribuir al Concilio el uso de los conceptos utilizados bajo una metafísica determinada, seguidamente señala que la concepción teológica de santo Tomás es la dominante en la teología clásica. De allí que se haya comprendido el cuerpo de Cristo bajo la teoría hilemórfica de la realidad.

Una vez expuesta la definición por parte de la Iglesia respecto a la Eucaristía, Zubiri se pregunta ies mantenible, con todo rigor, la idea de la sustancia de Aristóteles? ¿Son dos realidades, la una, los accidentes de la especie, y la otra de la sustancia del cuerpo de Cristo, respecto de la cual los accidentes no tienen más que función de un continente, respecto de un contenido? Pero también caben preguntas

42 Curso «Reflexiones filosóficas sobre algunos problemas de teología», VIII lección.

43 «Si alguien dijere que, en el sacrosanto sacramento de la Eucaristía permanece la sustancia del pan y del vino a una con el cuerpo y la sangre de Nuestro Señor Jesucristo, y negara aquella admirable, y singular conversión de toda la sustancia del pan en cuerpo, y toda la sustancia del vino en sangre, permaneciendo, sin embargo, las especies del pan y del vino, a esta conversión que la Iglesia católica aptissime, aptamente, llama transubstanciación, que sea anatema».

44 Xavier Zubiri, El problema teologal del hombre: Dios, Religión, Cristianismo, 705. 
para teologías posteriores a Trento, como lo es la proveniente de la «antropología del signo» de Eduard Schillebeeckx O.P., donde se defiende que la presencia real y todo el sacramento de la Eucaristía ha de hacerse con unas categorías no físicas sino sacramentales. Zubiri no niega la verdad de aquella teología, la cual apunta a la razón formal de la Eucaristía en cuanto oblación, por tanto, no es errado utilizar los términos de transfinalización y una transignificación, sin embargo, esto no resta que haya una estricta transustaciación, pero tampoco ello aclara en qué consiste la presencia real de Cristo en la Eucaristía. Nuestro autor afirma que «la Iglesia, no impone el concepto aristotélico de sustancia, y no excluye la verdad de la Teología en la forma en que acabo de exponer, y exhorta de una manera temática a una profundización del tema, cada vez mayor ${ }^{45}$. Es lo que da pie a formular su propia vía desde otra metafísica: la metafísica de la sustantividad.

Observamos que la reflexión filosófica de estos años (1967-1971) aporta, desde la metafísica de la sustantividad, una respuesta a dónde acontece lo misterioso del misterio eucarístico este radicaría en la apertura del sistema sustantivo de la especie del pan a la sustantividad del cuerpo de Cristo, que otorga la presencia no solo significativa sino real de Cristo en el pan eucarístico, así la unidad coherencial del pan consagrado es insustantiva, su sustantividad la otorga el cuerpo de Cristo, una unidad superior y misteriosa. Sin embargo, se entrevé que la metafísica de la sustantividad no alcanza conceptualmente a aproximarse con radicalidad a la razón formal de la Eucaristía.

La síntesis del hombre y Dios es lo que Xavier Zubiri busca por tantos años y que se puede rastrear desde sus tempranos textos de la década del treinta, por ejemplo la reflexión acerca de la teología de los Padres griegos que expone detalladamente en «El ser sobrenatural: Dios y la deificación en la teología paulina» (1934-1935) donde nos

45 Curso «Reflexiones filosóficas sobre algunos problemas de teología», VII lección, Madrid, 7 de diciembre de 1967. Texto inédito 
muestra la íntima articulación entre la realidad y su fuente. Lo creado se constituye en el «lugar» donde Dios, siendo distinto, está dándoles su ser y manteniéndolas en él; de este modo la realidad humana está llamada a la deificación. Esta idea pervive a lo largo de su obra y será el concepto de actualidad el que dará mejor aproximación direccional a la razón formal de la Eucaristía. Si nos detenemos en los textos de diversa data, confirmaremos la idea que el concepto de actualidad, el que mejor alcanza esta síntesis.

El texto de 1967, respecto a la razón formal de la Eucaristía, comienza destacando la encarnación como la culminación de la plasmación ad-extra de la vida trinitaria. Sin embargo, ella no debe comprenderse como un estar ahí simplemente entre nosotros, sino la razón de ser de la encarnación es incorporarnos a todos en la vida trinitaria y la razón formal de la Eucaristía es la prolongación de la encarnación.

La Encarnación era la prolongación de la vida trinitaria en los hombresuna prolongación en qué consiste que Dios se da personalmente a la realidad humana, y en ella a la vida, la Historia y las otras realidades físicas. Pues bien, hay que añadir que mediante la Eucaristía, nos incorporamos realmente a la unidad del Padre, adquiriendo una nueva sustantividad por Cristo. En este sentido la Eucaristía es una prolongación directa, voluntaria y libérrima, es una prolongación directa de aquello en que consiste la Encarnación, a saber, la presencia real de Cristo en las especies eucarísticas ${ }^{46}$.

La razón formal de la Eucaristía es la incorporación del hombre a la vida trinitaria de Dios mismo, a ello atiende el autor desde su metafísica de la sustantividad. La finalidad de la estructura misma de la Eucaristía es la comunicación interpersonal de Cristo con cada una de las personas humanas. Cristo se da a cada persona humana, y esta donación se hace, como se hace toda donación de unas personas a otras. Y ícómo lo realiza?

46 Curso «Reflexiones filosóficas sobre algunos problemas de teología», VIII lección, Madrid 11 de diciembre de 1967. 
En este texto de 1967 la incorporación a la vida de Cristo por medio de la Eucaristía, como prolongación de la Encarnación, se afirma como una donación personal, que afecta nuestra propia sustantividad como realidad personal, surge una nueva sustantividad. Pero, no explicita cómo aquello acontece. Podríamos deducir que pudiera ser explicitado del mismo modo como cambia la sustantividad del pan, o sea la presencia de Cristo en el pan consagrado al ser ingerido por el creyente provocaría una apertura de su sustantividad a otra superior. Sin embargo, acá no lo explícita, acaso porque la transformación de la sustantividad humana requiere otro tratamiento distinto que la del pan, por ser el hombre una realidad personal. Si Dios se dona personalmente, tendremos otro tipo de causalidad respecto a la de las realidades no personales.

Será en el texto de 1971 donde se detendrá a explicar cómo, desde una metafísica de la sustantividad, puede atenderse conceptualmente la incorporación de Cristo al ser de la realidad humana, utilizando el término de «elevación», una conversión misteriosa de la sustantividad del pan. Cristo toma para sí las notas del pan para darlo a los hombres.

Por consiguiente, las notas tienen justamente la función de ser la actualización de este «dar-a». Serían, si ustedes me permiten la expresión, un único, excepcional, gigantesco pero auténtico caso de constructo-dativo. No son «notas-de», sino «notas-a»: notas de la unidad de Cristo a cada uno de los hombres que la recibe. De ahí que las especies eucarísticas, como actualización de la unidad coherencial primaria en que la realidad de Cristo radical y formalmente consiste, sean la actualización dativa de esa unidad ${ }^{47}$.

Estas afirmaciones no solo son posibilitadas por una comprensión de la realidad desde el concepto de sustantividad, sino también por una concepción del cuerpo que aparecerá en 1973 en todo su esplendor con el texto «El hombre y su cuerpo $»^{48}$. Donde el cuerpo mienta actualidad, y en 1971 bien lo barruntaba de este modo: «La

47 Xavier Zubiri, El problema teologal del hombre: Dios, Religión, Cristianismo, 708.

48 Xavier Zubiri, «El hombre y su cuerpo», en Escritos menores (1953-1983), 103-116. 
corporeidad consiste formalmente en conferir a la realidad de quien es cuerpo una presencia actual, una consistencia interna y una expresión ${ }^{49}$.

Podemos ver que las ideas presentadas en estos dos cursos, respecto a la Eucaristía, son solidarias con su obra de 1963 Sobre la esencia, pero aún creemos que no alcanza la radicalidad que le otorgará su pensamiento filosófico final, donde la razón formal de la Eucaristía quedará bajo el concepto de co-corporeidad o co-actualidad, término que da cuenta direccionalmente de mejor manera la razón formal de la Eucaristía como prolongación de la incorporación del hombre a la vida trinitaria otorgada por la Encarnación. Vayamos a su presentación.

2.3.2 «Reflexiones teológicas sobre la Eucaristía» (1980). La Eucaristía como co-actualidad o co-corporeidad

Sobre este tema estrictamente teológico propone de manera explícita seguir una vía metafísica bastante simple y atendida a los nudos datos de la $\mathrm{fe}^{50}$. ¿ Qué quiere decir con una metafísica simple? ¿Cuáles son los nudos datos de la fe?

Zubiri afirma que tanto la teología especulativa como la teología bíblica se articulan desde una metafísica determinada, la bíblica al interior de la metafísica semítica, la cual quiere decir con sus conceptos, «que es lo que está revelado» ${ }^{51}$, a diferencia de la especulativa que «"quiere decir" lo que "ya se sabe"»" la teología especulativa recurre a conceptos de la filosofía griega antigua, la cual se origina en un horizonte de intelección (horizonte griego de la movilidad) radicalmente diferente del horizonte cristiano (horizonte teológico de la creación o de la nihilidad). Por ello es necesario ponerlos en cuestión, con el objetivo de ver si en el

49 Xavier Zubiri, El problema teologal del hombre: Dios, Religión, Cristianismo, 705.

50 Xavier Zubiri, El problema teologal del hombre: Dios, Religión, Cristianismo, 787.

51 Xavier Zubiri, El problema teologal del hombre: Dios, Religión, Cristianismo, 18.

52 Cf. Xavier Zubiri, El problema teologal del hombre: Dios, Religión, Cristianismo, 18. 
desarrollo de la filosofía surgen otros conceptos direccionales que puedan dar mejor cuenta de esos nudos datos de la fe.

De lo que aquí se trata es hacer teología y a ella aporta la filosofía zubiriana los conceptos claves de su filosofía primera, estos son: sustantividad, actualidad y corporeidad. Siendo un texto de su época madura la primacía la tienen estos dos últimos, los cuales para él provienen de la atención a los hechos mismos.

En cuanto a los nudos datos de la fe aquí ya no se trata de la fe desde el análisis teologal ${ }^{53}$, sino la fe en concreción al interior del Cristianismo. Pero dicha concreción tiene siempre como punto de partida la experiencia de la religación, es ella la que posibilita que se concretice esa constitutiva inquietud humana que lleva el problema teologal. «La realidad es fundante de una realidad personal por apoderamiento según el poder de lo real» ${ }^{54}$. La experiencia religiosa no es más ni menos que la configuración de la vida desde la experiencia de la religación como experiencia de ultimidad de lo real y esta experiencia es solo una posibilidad entre otras ${ }^{55}$.

Para Zubiri el cristiano no preexiste al acontecimiento que declara, ese acontecer de Cristo se da como deiformación una configuración del hombre en Cristo. Ello trae una concepción del cristianismo como una religión de deiformación ${ }^{56}$. La deiformación es el fundamento de la revelación, porque lo que se revela es la donación física de Dios como posibilidad de configuración del ser personal, los que han hecho probación física de Cristo configurándose en Él

«Sería análisis por ser descripción de un hecho, el hecho de la religación, inmediatamente actualizado en los actos humanos y accesible a cualquiera con independencia de su confesión religiosa y sería teologal por versar sobre un hecho que abre y plantea para todos el problema de Dios. Este sería el punto de partida fundamental de los estudios de Zubiri sobre temas religiosos y teológicos. Y probablemente sería esta también la aportación más novedosa de Zubiri a la filosofía de la religión», Jordi Corominas, «Filosofía de la religión y teología de raigambre zubiriana», Revista Catalana de Teología, 1, XXVII (2002): 83.

54 Xavier Zubiri, El hombre y Dios (Madrid: Alianza, 2012), 95.

55 Sobre el tema de la religación y la configuración personal, ver Eugenia Colomer y Ricardo Espinoza, «Cuerpo y religación en Xavier Zubiri», Teología y Vida, 2, 56 (2015), 247-270.

56 Cf. Xavier Zubiri, El problema teologal del hombre: Dios, Religión, Cristianismo, 31-32. 
lo proclaman. Es esta experiencia la que entrega esos nudos datos de la fe proclamados por el logos kerygmático.

Como hemos visto la metafísica clásica ha pensado la presencia real de Cristo en la Eucaristía desde los efectos del pan, sin hacer mayor cuestión del modo de la presencia real de Cristo, serán los aportes de la actualidad y la corporeidad los que permitan afirmar la presencia de Cristo como actualidad corpórea fundamento de la transsubstantivación y posibilitando la razón formal de la Eucaristía como co-corporeidad y co-actualidad con quien la recibe.

Aquí cuando trata el modo de la presencia de Cristo en la Eucaristía se detiene a examinar qué es actualidad, qué es el cuerpo humano y el modo de la presencia real del cuerpo de Cristo en el pan consagrado. Nosotros seguiremos ese mismo orden.

Los caracteres propios de la actualidad son: un momento real y físico, por ello la presencia de Cristo aquí no es simbólica ni metafórica, como tampoco moral ni una presencia de virtualidades dinámicas, actualidad mienta un físico estar siendo por ello otro carácter es el de un momento que admite un devenir:

Ante todo, el devenir de actualidad no es el devenir de propiedades, pero es, sin embargo, un físico devenir: se llega a tener actualidad o a dejar de tenerla sin el menor cambio de propiedades en quien es actual: el devenir de actualidad no es un devenir de actuidad ${ }^{57}$.

Este carácter dinámico de la actualidad no solo se comprende desde la realidad misma que deviene en actualidad, sino desde una realidad ya actual, cuya actualidad está fundada en un principio radical que la hace presente y puede tener muchas otras actualidades, que nuestro autor llama actualidades ulteriores, como modalizaciones de aquella actualidad radical. Aparece el devenir como un «hacerse actual» y de allí los ejemplos de cómo Dios mismo se hace actual en un hombre justo, en la encarnación, o bien el hombre actual como padre, hermano, médico, etc. Para Zubiri estos son modos diversos 
de la actualidad radical, en el caso del hombre su cuerpo como corporeidad. «Estas modalizaciones son la expresión real y física de la riqueza radical del principio de actualidad $»^{58}$. En Cristo una de estas modalizaciones es su actualidad en el pan eucarístico, esto significa que toma el pan como principio de actualidad sin perder su principio intrínseco y formal de actualidad que es su cuerpo, este es el fundamento de su actualidad en el pan-alimento. Cristo está presente en el pan, pero es actual en el pan, porque ya es actual en su persona. Hay una común actualidad, el pan-alimento principio de actualidad de Cristo y Cristo actual en ese pan. "Pero en virtud de este principio [cuerpo] formal y radical. Cristo puede "extender" (perdóneseme el verbo) su propia actualidad formal, puede modalizar ulteriormente su principio de actualidad asumiendo el pan-alimento como principio de actualidad ${ }^{59}$. En el hombre ese principio es el cuerpo y como Cristo lo es, su principio de actualidad es el cuerpo.

La presencia de Cristo en la Eucaristía hace del pan-alimento principio radical de su actualidad, en esto consiste lo misterioso del Misterio, hacer del pan-alimento su corporeidad, de allí que hay una actualidad común de Cristo y el pan-alimento.

Por el primer aspecto: «esto es mi cuerpo», es decir, «esto (el pan aquí) (es) el cuerpo de Cristo (es yo mismo)». Por el segundo aspecto: «mi cuerpo es esto», es decir, «mi cuerpo» (Cristo mismo), (es) esto aquí. Esta comunidad es justo la esencia de la presencia real ${ }^{60}$.

Porque Cristo se hace actual en el pan-alimento extendiendo su actualidad intrínseca a él, por causa de la trans-actualización como un devenir de actualidad, este se abre a otra sustantividad, la sustantividad de Cristo. La presencia real de Cristo en el pan, la actualidad común, es los que constituye la llamada presencia sacramental.

La primacía que va adquiriendo el concepto de actualidad se debe a que es aquel concepto el que mejor expresa la razón formal 
de la Eucaristía. Porque la razón de ella no se agota en su razón radical que es la presencia real de Cristo en el pan consagrado, sino hay otra razón, la que Zubiri denomina en este texto «razón formal», cual es la actualidad común de Cristo y quienes comen de ese pan, Pues bien, el principio radical de actualidad es la corporeidad. Cristo se actualiza en ese pan para entregarse a los hombres y ser una misma actualidad, un solo cuerpo. Ser un mismo cuerpo implica configurarnos con Él y en Él.

Si dejamos ese pan consagrado en la mera sustantividad de Cristo podemos quedarnos en un mero alarde metafísico, un milagro portentoso, pero solo eso «la Eucaristía no es solo la presencia real de Cristo en el pan, sino que es formalmente cuestión de la unidad del que recibe la Eucaristía con Cristo. Esta unidad es unidad de actualidad: Cristo se hace actual en mí y yo me hago actual con Cristo» ${ }^{61}$.

Cristo quiere darse a quienes acepten comer ese pan, y Cristo en tanto Dios mismo nunca da algo sino Él mismo: «Esto (aquí) Yo mismo», ese Yo mismo dado corporalmente para tocar nuestro propio cuerpo, y en ese acto íntimo compartir un mismo acontecer, se tocan dos cuerpos y surge uno solo. Es la experiencia que san Pablo bellamente expresa: «Y ya no vivo yo, sino Cristo vive en mí. Esta vida en la carne, la vivo en la fe del Hijo de Dios que me amó y se entregó a sí mismo por mí» (Ga 2,20). En esto consiste la radicalidad de la experiencia cristiana ser co-corporeidad, un mismo cuerpo con Cristo.

Esta co-actualidad como co-corporeidad no afecta solo nuestra dimensión individual sino afecta integralmente lo que somos seres individuales, pero también sociales e históricos, de allí la importancia de la Eucaristía como banquete.

Cristo se hace actual en el pan como alimento espiritual y el alimento se come, en el comer hay que distinguir el nudo hecho de comer y el comer reunidos. Cristo dio de comer el pan en un banquete, la tradición de la Iglesia habla de banquete o ágape. «La Eucaristía es

61 Xavier Zubiri, El problema teologal del hombre: Dios, Religión, Cristianismo, 812. 
banquete, es ágape, y este ágape consiste en comunión personal con Cristo, y derivadamente en ser comunión personal con los demás» ${ }^{62}$. Ágape mienta la idea del ser de Dios en el Nuevo Testamento; ágape es donación, esta idea es la que prevalece desde la teología de los Padres Griegos y de la que Zubiri no niega su predilección. «La ágape es el amor personal en que el amante no busca nada, sino que al afirmarse en su propia realidad sustantiva, la persona no se inclina por naturaleza, sino que se otorga por liberalidad ${ }^{63}$. Por tanto no basta decir que estamos llamados los cristianos a configurarnos con Cristo, hay que preguntarse por el ser de Cristo, en tanto Dios mismo encarnado, bajo la concepción dinámica del ser de la cual es solidaria la metafísica de los Padres Griegos y la de Zubiri.

Podemos comprender el ser de Cristo como ágape y esta es la raíz formal de la Eucaristía. Recordemos que los hombres por su figura de instauración en la realidad de manera absuelta, pero que es cobrada. Es por esto que el hombre no solo es reduplicativamente «suyo» sino que es «suyo» frente a cualquier realidad, y este es el fundamento de la convivencia social. Solo los hombres pueden constituir una sociedad a través de la convivencia de un hombre con los demás los hombres. Pero hay diferentes modos de convivir ya sea de manera a-personal o bien de modo personal.

La sociedad es esencialmente una convivencia impersonal. Pero una persona puede estar vertida a otra persona no en tanto que otra, sino en tanto que persona. Esta convivencia no es sociedad: es una forma distinta de convivencia que he solido llamar «comunión personal» ${ }^{64}$.

Esta versión como «comunión personal» mienta ya no el Yo, en tanto ser individual sino el ser común y lo común es el «siendo» lo que personalmente se es, es unidad de actualidad. Siendo el cuerpo principio de actualidad, podemos hablar de una co-corporeidad.

Los partícipes del ágape, al adquirir una actualidad con Cristo, forman, por tanto, cuerpo con él y en su virtud su comunión personal con Cristo

\footnotetext{
62 Xavier Zubiri, El problema teologal del hombre: Dios, Religión, Cristianismo, 812.

63 Xavier Zubiri, Naturaleza, Historia, Dios (Madrid: Alianza, 2004), 465.

64 Xavier Zubiri, El hombre y Dios, 75.
} 
es precisa y formalmente incorporación al cuerpo de Cristo. Y como todos forman un mismo cuerpo con Cristo resulta que como nos dice San Pablo, que todos somos con-corpóreos en Cristo ${ }^{65}$.

A esta comunidad personal es lo que mienta el banquete eucarístico, no es una unidad por el simple hecho de estar presentes como otros, sino es un mismo siendo, es la probación física del ser de Cristo como ágape en la común actualidad corpórea.

En cuanto a la dimensión histórica del ser humano es el hombre el que tiene que tiene que hacerse cargo de la realidad y lo hace a través de sus acciones y si la historia es actualización de posibilidades será el hombre actualizado en Cristo el que lo hará presente en ella. Dios se hace presente en la historia y no es el gran ausente de ella.

\section{Conclusiones}

La Eucaristía es la prolongación de la Encarnación de Cristo, de allí que la razón formal de la Eucaristía sea la comunión personal de quien la recibe con Cristo. Es lo que mienta el banquete eucarístico, no es una unidad por el simple hecho de estar presentes como otros, sino es un mismo siendo, es la probación física del ser de Cristo como ágape en la común actualidad corpórea. Pero el ser humano no solo es una realidad individual y social, también es histórica. En cuanto a la dimensión histórica del ser humano es el hombre el que tiene que hacerse cargo de la realidad y lo hace a través de sus acciones y si la historia es actualización de posibilidades será el hombre actualizado en Cristo el que lo hará presente en ella. Dios se hace presente en la historia y no es el gran ausente de ella. Sobre Dios y la realidad histórica la teología latinoamericana ha reflexionado profundamente y no han sido menores los aportes de Xavier Zubiri.

Respecto a la presencia real de Cristo en la Eucaristía, la doctrina de la Iglesia Católica afirma que la presencia de Cristo en la Eucaristía es una presencia real, no es una presencia simbólica ni

65 Xavier Zubiri, El problema teologal del hombre: Dios, Religión, Cristianismo, 813. 
metafórica y lo misterioso de este misterio el Magisterio de la Iglesia y la teología lo ha tratado bajo la metafísica de la sustancia como transubstanciación. La metafísica clásica ha pensado la presencia real de Cristo en la Eucaristía desde los efectos del pan, sin hacer mayor cuestión del modo de la presencia real de Cristo.

La visión entificada de la realidad y la logificación de la inteligencia, las denuncias de Xavier Zubiri al horizonte de intelección occidental, apuntan a la descorporalización de la fe y objetivación de Dios. De allí que la Eucaristía puede quedar reducida a un mero alarde metafísico de Cristo, un milagro portentoso, pero solo eso. Si la razón formal de la Eucaristía es la configuración individual, social e histórica de quien la recibe con la persona de Cristo, el modo de aquella presencia debe ser coherente con ella. La Eucaristía, afirma Zubiri en reiteradas ocasiones, es la prolongación de la Encarnación, por tanto por ella nos incorporamos a la vida de Cristo, y ello implica un solo cuerpo, un solo ser. Dicha afirmación requiere otra visión del cuerpo y del ser. Atender al cuerpo fuera de cualquier estructura esencialista y más allá de una realidad sustantiva de notas psiquico-físicas, es el lugar del surgir de toda realidad. No hay experiencia posible sin realidad actual, sin ese físico estar corporal, no olvidemos que aprehendemos impresivamente la realidad y la realidad de Dios también. El cuerpo radicalmente mienta solo lugar de actualidad, actualidad del ser personal, de todas las cosas y de Dios mismo. Sin ataduras estructurales de ningún tipo queda libre para ser el lugar de la experiencia de Dios de manera siempre nueva, cuerpo que se desplaza junto a Dios por la creación revelándolo de modos diversos. Dios en Cristo se revela como «realidad siendo», de esto bien dan cuenta los relatos bíblicos, siendo Dios experiencia del hombre posibilita que seamos experiencia de Dios mismo en Cristo.

La presencia real de Jesucristo en la Eucaristía acontece en el ámbito de la fe, la cual Zubiri la comprende como conocimiento con entrega, respuesta a quien llama como una fuerza vis a tergo desde el fundamento de todo lo real, lo más otro y a la vez lo más 
cercano e íntimo en el hombre, es la respuesta a configurar de un modo nuestro ser; de allí que la Eucaristía no es una realidad ajena a la experiencia del cristiano, más bien es la experiencia sublime de serlo. Al participar sacramentalmente de la Eucaristía, la vida es Eucaristía. Cristo, por la acción litúrgica, actualiza su presencia: «Yo: mi cuerpo, Yo mismo». Por tanto, nosotros, partícipes de la Eucaristía, somos cuerpo de Cristo, ello se debe relevar, la presencia real, verdadera y sacramental tiene repercusiones eclesiológicas: la Iglesia es la participación de los iniciados en la Eucaristía en la que se actualiza el mandato de Jesús: hagan esto en conmemoración mía. Así, la pertenencia a la Iglesia no es del ámbito de la relación distante sujeto e Iglesia, sino de una relación vinculante personal, un solo cuerpo, un solo ser con Cristo.

\section{Bibliografía}

Aldazábal, José. La Eucaristía. Barcelona: Centre de Pastoral litúrgica, 2000.

Alluntis, Félix. «Reflexiones teológicas sobre la Eucaristía de Xavier Zubiri». Estudios Eclesiásticos 63, 246 (1988): 285-312.

Borobio Dionisio. Eucaristía. Madrid: Biblioteca de Autores Cristianos, 2005.

Casel, Odo. El misterio del culto cristiano. San Sebastián: Dinor, 1953.

Colomer, Eugenia y Espinoza, Ricardo. «Cuerpo y religación en Xavier Zubiri». Teología y Vida 2, Vol. 56 (2015): 247-270.

Concilio Vaticano II, Constitución Sacrosanctum Concilium sobre la sagrada liturgia. Madrid: Biblioteca de Autores Cristianos 1993. Consultada en mayo 27, 2017, http://w2.vatican.va/ content/john-paul-ii/es/apost_exhortations/documents/ hf_jp-ii_exh_22011999_ecclesia-in-america.html.

Corominas, Jordi. «Filosofía de la religión y teología de raigambre zubiriana». Revista Catalana de Teología 1, Vol. xxviI (2002): 67-105. 
De Lubac, Henri. Corpus Mysticum. L'eucharistie et l'Eglise au Moyen Âge. Paris: Éditions du Cerf, 2010.

Denzinger, Heinrich y Hünermann, Peter. El Magiestrio de la Iglesia. Enchiridion Symbolorum definitionum et declarationum de rebus fidei et morum. Barcelona: Herder, 2006.

Espinoza, Ricardo, Ascorra Paula y Vargas Esteban. «Realidad y actualidad. Una primera aproximación al tema del cuerpo». ARBOR Ciencia, Pensamiento y Cultura 189 (2013). Consultada en diciembre 15, 2016. Doi: http://dx.doi. org/10.3989/arbor.2013.760n2003.

González, Antonio. «Ereignis y actualidad». En Desde Zubiri. Editado por Diego Gracia, 103-192. Granada: Comares, 2004.

Gracia, Diego. Voluntad de verdad. Para leer a Zubiri. Barcelona: Labor, 1986.

Millás, José M. «Zubiri y la Eucaristía. La aplicación de los conceptos de actualidad y sustantividad a la teología de la Eucaristía». Gregorianum 2, Vol. 81 (2000): 249-285.

Pablo VI. Carta Encíclica Misteryum fidei, 3 de septiembre de 1965. Consultada en mayo 27, 2017. http://w2.vatican.va/content/ paul-vi/es/encyclicals/documents/hf_pvi_enc_03091965 mysterium.html.

Rahner, Karl. Escritos de teología, Tomo Iv. Madrid: Taurus Ediciones, 1964.

Santa Sede, Vaticano. «Exhortación apostólica postsinodal Ecclesia in America». Consultada en mayo 27, 2017. http://w2.vatican. va/content/john-paul-ii/es/apost_exhortations/documents/ hf_jp-ii_exh_22011999_ecclesia-in-america.html.

Santa Sede, Vaticano. Concilio Vaticano II, Constitución Sacrosanctum Concilium sobre la sagrada liturgia. Madrid: Biblioteca de Autores Cristianos, 1993. 
Sayés, José A. La presencia real de Cristo en la Eucaristía. Madrid: Biblioteca de Autores Cristianos, 1976.

Sayés, José A. «La transubstanciación en Zubiri: ¿̇Realismo o fenomenología?». Ciencia Tomista 127 (2000): 393-414.

Schillebeeckx, Edward. The Eucharist. New York: Burns \& Oates, 1968.

Sotil, Francisco. «La conceptuación zubiriana de la presencia eucarística de Cristo: críticas y valoración de las mismas». The Xavier Zubiri Review 9 (2007): 19-68.

SS Juan Pablo II. Exhortación apostólica postsinodal Ecclesia in America. Consultada en mayo 27, 2017. http://w2.vatican. va/content/john-paul-ii/es/apost_exhortations/documents/ hf_jp-ii_exh_22011999_ecclesia-in-america.html.

Torres Queiruga, Andrés. «La Eucaristía, encuentro vivo con el Señor». Horizonte: revista de Estudos de Teologia e Ciências da Religiao 12, Vol. 6 (2008): 21-40. Consultada en enero 7, 2017. https://dialnet.unirioja.es/servlet/articulo? codigo $=4740639$.

Zubiri, Xavier. El hombre y Dios. Madrid: Alianza, 2012.

Zubiri, Xavier. «El hombre y su cuerpo». En Escritos menores (19531983). Madrid: Alianza, 2006.

Zubiri, Xavier. El problema teologal del hombre: Dios, Religión, Cristianismo. Madrid: Alianza, 2015.

Zubiri, Xavier. Inteligencia Sentiente/Inteligencia y Realidad. Madrid: Alianza, 1980.

Zubiri, Xavier. Inteligencia y logos. Madrid: Alianza, 1982.

Zubiri, Xavier. Naturaleza, Historia, Dios. Madrid: Alianza, 2004.

Zubiri, Xavier. «Respectividad de lo real». En Escritos menores (19531983). Madrid: Alianza, 2006. 